\title{
An Investigation into Students' Approaches towards Solving word Problems in Mathematics
}

\author{
Muhammad Mukhtari Hussaini, Abba Adamu \\ Mathematics Department College of Education, Azare Bauchi State
}

\begin{abstract}
This paper attempts to provide some insights on students' various approaches towards solving words problems in Mathematics. 15 students were randomly selected from SSIII students of Demonstration Secondary School, Azare Bauchi State. Three (3) visits were scheduled to the school for interview, questions administration on words problem and discussions, the findings revealed that the students lack necessary knowledge and skills to solve word problems. It is recommended that teachers should employ various heuristics when teaching words problem to enable the students develop necessary skills needed to solve words problems.
\end{abstract}

\section{Introduction}

Word problem solving is an integral part of mathematics. It requires solid background knowledge of concepts, facts, structures, principles and procedures. Adams (2003:286) states that reading mathematics is a multifaceted task because the reader is "challenged to acquire comprehension and mathematical understanding with fluency and proficiency through the reading of numerals and symbols, in addition to words. Thus, solving word problems calls for an initial identification of problem, relation of problem to known idea, identification of structure of the problem, carrying out necessary computations and obtaining solutions, putting the result in a generalized form and analyzing the procedure leading to the solutions.

James (2002) said there is a dynamic and cyclic nature of genuine problem solving. A student may begin with a problem and engage in thought and activity to understand it. The student attempts to make a plan and in the process may discover a need to understand the problem better. Or when a plan has been formed, the student may attempt to carry it out and be unable to do so.

Problem solving approach which is quite good for solving word problems and is not only a vehicle for developing logical thinking, it can provide students with a context for learning mathematical knowledge, can enhance transfer of skills to unfamiliar solutions and it is an aesthetic form in itself. Thomson (1985); said, students can become even more involved in problem solving by formulating and solving their own problems, or by rewriting problems in their own words in order to facilitate understanding. It is of particular importance to note that they are encouraged to discuss the process which they are undertaking, in order to improve understanding, gain new insight into the problem and communicate their ideas.

Researchers (Adler, 2004; Luneta, 2008 and Setati, 2005) had documented some reasons for errors that learners display and misconceptions they posses which contributed to their poor performances. Others (Sello, 2011) wrote on effective instructional approaches used by teachers to teach. A substantial body of literature has documented that both children and adults posses a rich store of informal knowledge related to variety of mathematical content domains that they are able to successfully draw upon to solve everyday problems both outside and inside school settings. Carraher, Carraher \& Schliemann, 1987; Love, Murtaugh \& dela Rocha 1984; Saxe, 1988; Scribber, 1984 in Nancy (1990).

The research work is aimed at investigating into the various approaches exhibited by students on solving word problems. Obviously, informal knowledge could be used in solving such questions; therefore, the subjects' informal knowledge that could be of help would be assessed. Comparison would be made between procedures that yielded correct solutions of the problem exhibited by the students.

\section{Participants And Procedures}

The target population consists of all the Senior Secondary III students. However, due to the nature of the research design (qualitative) 15 students were randomly selected from those willing to participate in the research from among the three classes of Demonstration Secondary school, Azare, Bauchi State.

Three (3) visits were arranged, the first visit scheduled on $31^{\text {st }}$ January, 2013 was for a familiarization, discussion and selection of subjects. A thorough discussion was made between the researchers and the SSIII Mathematics teacher with regard to the following areas; coverage of content area, his views regarding the general attitude of his students towards mathematics, specifically what he can say about word problems, performance of his students, for how long has he been with the students. He said with the introduction of the new curriculum some topics that are to be taught in SSIII have now been slotted to SSII and vice-versa. But not 
withstanding he covered what is expected of him in SSII using the replaced curriculum. He said the students have positive attitude towards the subject and he started to handle them while in Senior Secondary level.

The purpose of the visit was explained to each of the three (3) classes, students who wished to participate raised their hands and were moved to a different class for sampling. Before the sampling was conducted, three (3) male and three (3) female students were interviewed individually. The interview centred on; at what level did you start learning word problems? Did you like it then? What of now? Do you know some steps that you need to follow when answering word problems? Which do you like most between word problems and straight forward computations? The virtually responded in same words; they started coming across word problems in JSS II. Only one said he first came across it in SS II. Most of the students interviewed said they did not like word problems and many still do not like it. The students openly said that they prefer computational mathematics to word problems.Finally, 15 students were sampled for the questions administration.

The second visit was to administer four questions on word problems that were extracted from the past West African Examination Council (WAEC) questions to the sampled students.

The students were given the questions and were asked to read and answer them. A space was provided under each question for the students to show their workings. The researchers asked the students to state all the details of their workings and were allowed to use calculators to ease their calculations. None of the students complained any ambiguity with the questions or asked any support from the researchers.

Letters were assigned to the students as identification code for the purpose of assessing what they wrote. Two aspects were observed for each question and for each student - one the correctness of the answer and two; whether the student followed correct procedure or not. Students were labeled A, B, C, ........... T. Two keys $\sqrt{ }$ and $\mathrm{X}$ were used for correct (answer/procedure) and wrong (answer/procedure) respectively. While blank spaces indicate 'no attempt'.

\section{Results And Discussion}

Table 1: Performance in questions (shaded cells indicate not attempted)

\begin{tabular}{|c|c|c|c|c|c|c|c|c|}
\hline & \multicolumn{2}{|c|}{ QUES1 } & \multicolumn{2}{|c|}{ QUES2 } & \multicolumn{2}{|c|}{ QUES3 } & \multicolumn{2}{|c|}{ QUES4 } \\
\hline & ANS & PRO & ANS & PRO & ANS & PRO & ANS & PRO \\
\hline $\mathrm{A}$ & $\mathrm{X}$ & $\square$ & $\mathrm{X}$ & $\mathrm{X}$ & $\mathrm{X}$ & $\mathrm{X}$ & $\mathrm{X}$ & $\mathrm{X}$ \\
\hline B & $\mathrm{X}$ & $X$ & & & & & $\mathrm{X}$ & $X$ \\
\hline $\mathrm{C}$ & $\mathrm{X}$ & $X$ & $X$ & $\mathrm{X}$ & $\mathrm{X}$ & $X$ & $\mathrm{X}$ & $\mathrm{X}$ \\
\hline D & $\mathrm{X}$ & $X$ & $\mathrm{X}$ & $X$ & $X$ & $X$ & $\mathrm{X}$ & $X$ \\
\hline $\mathrm{E}$ & $\mathrm{X}$ & $X$ & $X$ & $X$ & $X$ & $X$ & $X$ & $X$ \\
\hline $\mathrm{F}$ & $X$ & $\square$ & $X$ & $X$ & $X$ & $\square$ & $\mathrm{X}$ & $X$ \\
\hline $\mathrm{G}$ & $\mathrm{X}$ & $\mathrm{X}$ & & & $\mathrm{X}$ & $\mathrm{X}$ & $\mathrm{X}$ & $\mathrm{X}$ \\
\hline $\mathrm{H}$ & $X$ & $X$ & $\mathrm{X}$ & $\mathrm{X}$ & $X$ & $X$ & $\mathrm{X}$ & $X$ \\
\hline I & $\mathrm{X}$ & $\mathrm{X}$ & $\mathrm{X}$ & $X$ & $\mathrm{X}$ & $\mathrm{X}$ & $\mathrm{X}$ & $\mathrm{X}$ \\
\hline $\mathrm{J}$ & $X$ & $\square$ & $X$ & $\square$ & $X$ & $X$ & $X$ & $X$ \\
\hline $\mathrm{K}$ & $\square$ & $\square$ & & & $\mathrm{X}$ & $X$ & $\mathrm{X}$ & $X$ \\
\hline $\mathrm{L}$ & $\mathrm{X}$ & $\mathrm{X}$ & $\mathrm{X}$ & $\mathrm{X}$ & & & $X$ & $X$ \\
\hline $\mathrm{M}$ & $\mathrm{X}$ & $\mathrm{X}$ & $\mathrm{X}$ & $X$ & $\mathrm{X}$ & $\mathrm{X}$ & $X$ & $X$ \\
\hline $\mathrm{N}$ & $\mathrm{X}$ & $\mathrm{X}$ & $\mathrm{X}$ & $X$ & $\mathrm{X}$ & $\mathrm{X}$ & $\mathrm{X}$ & $\mathrm{X}$ \\
\hline $\mathrm{O}$ & $\mathrm{X}$ & $\mathrm{X}$ & $\mathrm{X}$ & $X$ & $X$ & $\mathrm{X}$ & $\mathrm{X}$ & $\mathrm{X}$ \\
\hline
\end{tabular}

One can easily infer from the table that the students struggled with the questions. Analysis of the questions shows that all the 15 students (100\%) attempted questions one and four. Question one is a word problem on measurement which leads to a simultaneous equation and question four is a word problem involving ratio and also leading to simultaneous equations. 12 students (80\%) attempted question two; which is a word problem on percentage leading to simple equation. While 13 students (87\%) attempted question three; which is a word problem on simple interest leading to simultaneous equations.

However, only one student was able to get question 1 correctly; and only four out of the fifteen students $(27 \%)$ followed the correct procedure for solving the question. They also fared no better in question 2, as only one student followed a correct procedure; however he could not get the correct answer. Furthermore, about three students did not even attempt the question. The same with question 3 where only one student followed correct procedure and two students did not attempt it. Despite all students attempted question 4; none of them followed correct procedure talk less of getting a correct answer.

In general only four students $(27 \%)$ were able to follow correct procedures in their attempt to solve the questions. These are students $\mathrm{A}, \mathrm{F}, \mathrm{J}$ and $\mathrm{K}$ followed correct procedure in question 1 , while in addition $\mathrm{J}$ followed correct procedure in question 2 and $\mathrm{F}$ in question 3.

For these students their workings on these questions are presented here in this paper for simple analysis.

Student A answered question 1 as follows: 


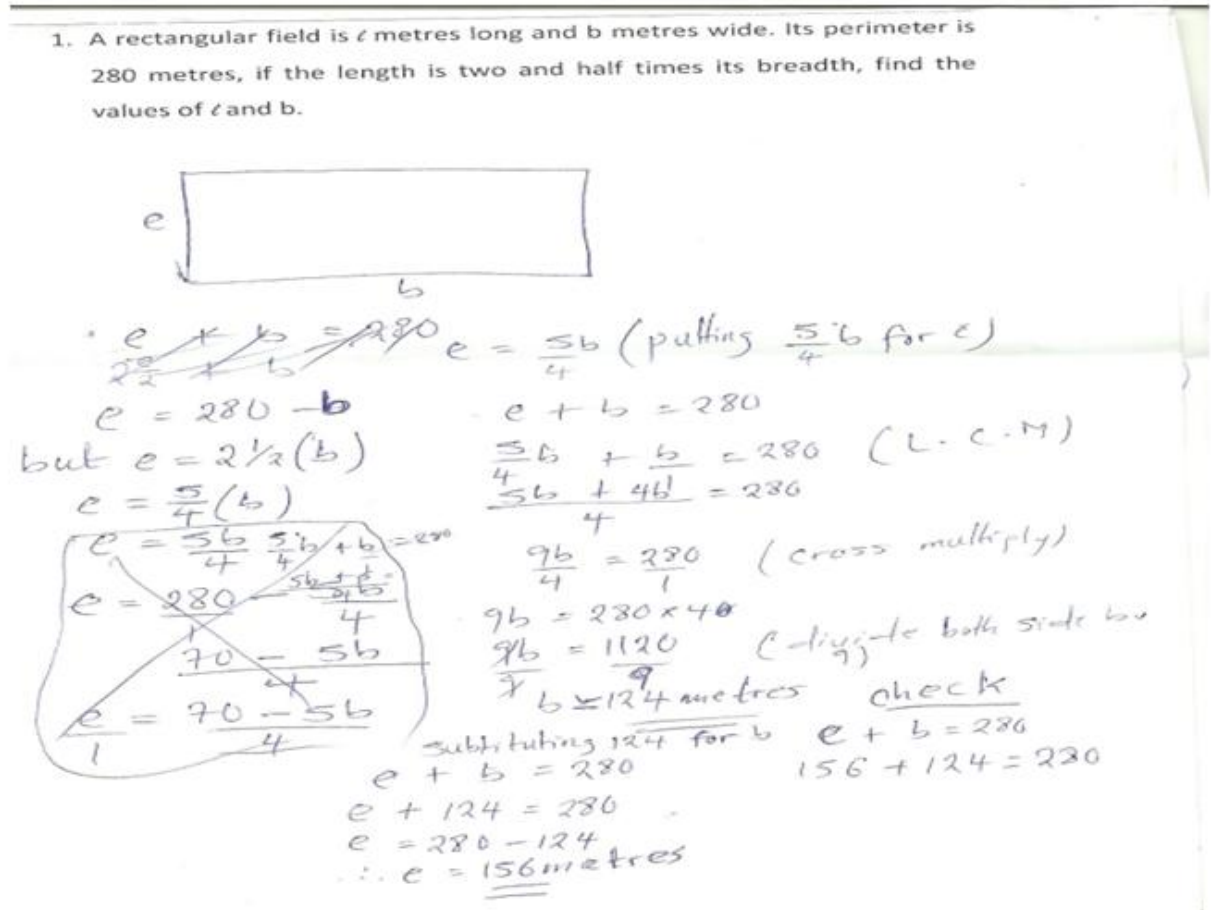

The student was able to connect the relationship between the length and the breadth but could not convert the mixed number $2 \frac{1}{2}$ to correct improper fraction; and that could be why the student could not get the correct answer. The student was able to use the common phrases usually used in solving problems like "cross multiply", "divide both sides" etc. The student also drew a diagram may be to help her deduce some facts about the problem. However, during a discussion with the student, she responded that the diagram was just there, not for anything. And when asked whether she had ever come across a question like this, she responded that she never. On whether she was ever taught a question on word problem leading to simultaneous equation, the response was 'yes'. When asked whether question one would lead to simultaneous equation, she responded yes and gave her reason, "we have two unknown variables". It was only during the discussion that the student understood that the problem will lead to simultaneous equations. When she was asked whether it is necessary to study relationship between variables in forming a solution the students responded 'yes it is necessary'. The student further responded 'yes' on the question 'whether there is need to recall any formula in solving the question'.

Student $\mathrm{F}$ answered question 1 as follows:

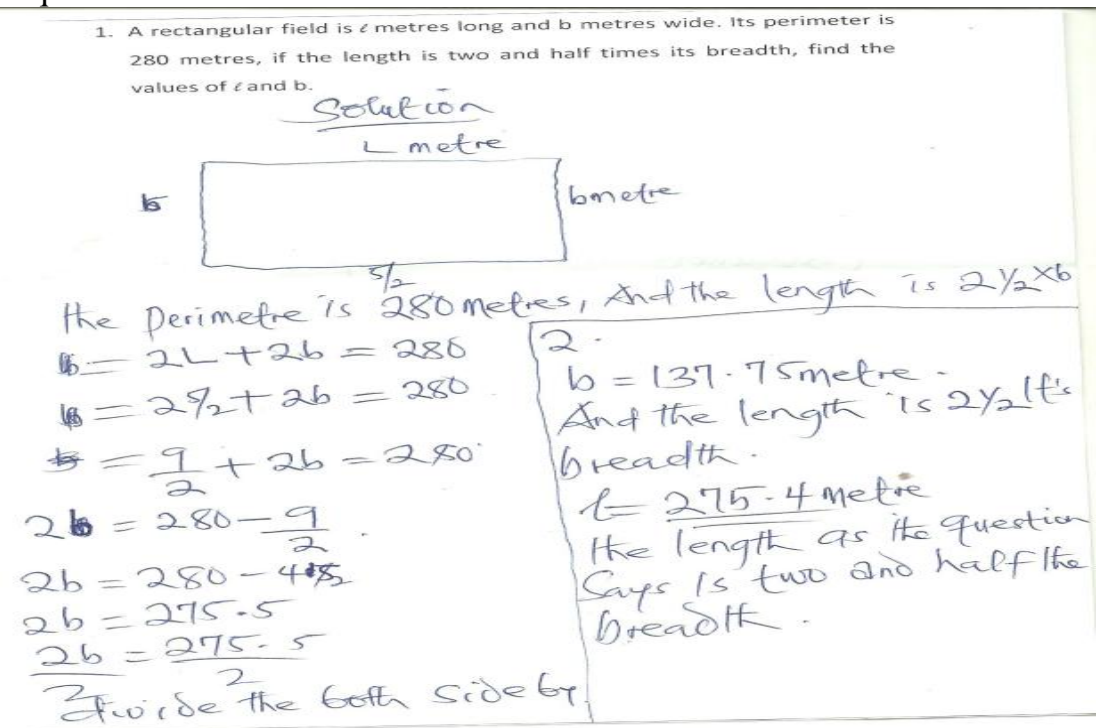


The student was able to connect the relationship between the length and the breadth but did a wrong substitution in line 2, which led to wrong answer.During a discussion with the student, he responded that the diagram he drew was necessary because it will help him in solving the problem. The student also responded that he had never come across a question like that but somehow a question related to it. He also responded that there is need to know the relationship between variables. On whether he was ever taught problem leading $\backslash$ to simultaneous equation, he responded 'yes'. However, when asked whether question one would lead to simultaneous equation, he responded 'no, it will not lead to simultaneous equation'. However, his workings show some element of simultaneous equations. The student also agreed with the need for using formula in solving the question.

The student also attempted question 3 as follows:

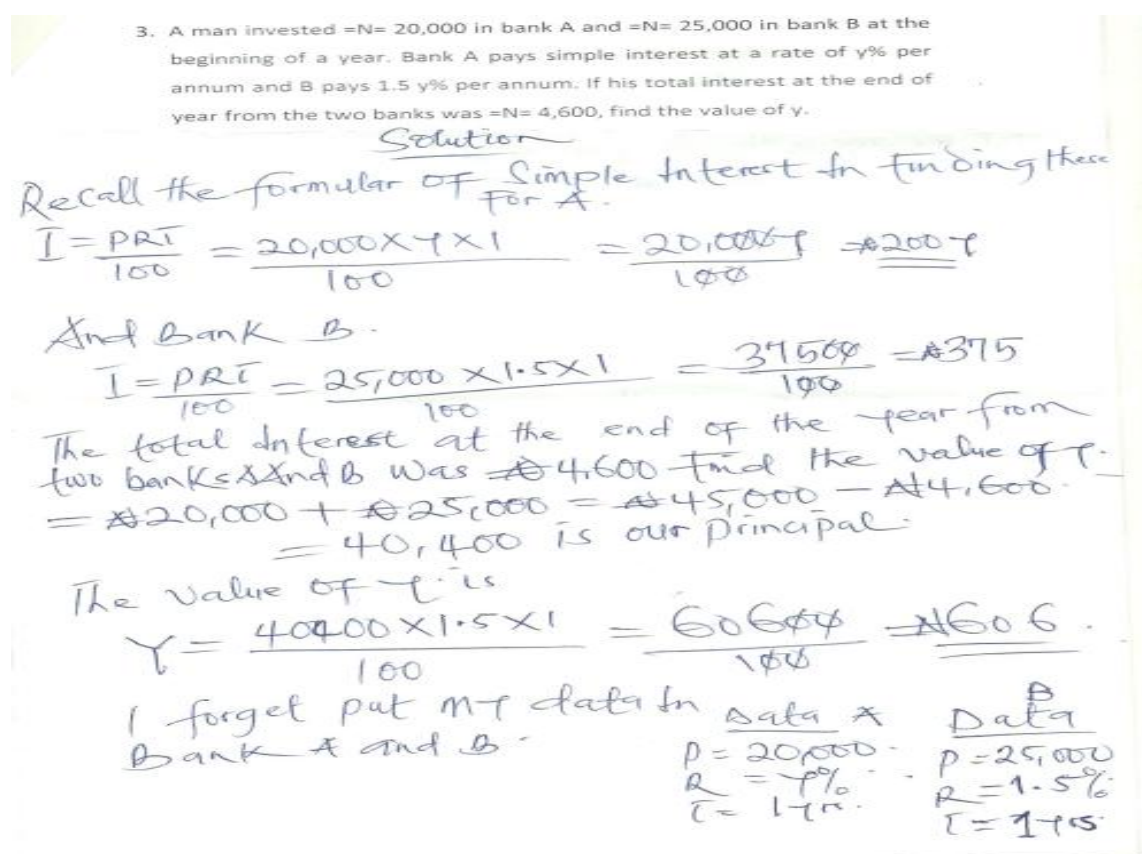

The student was able to recall the need for using formula for simple interest, did the substitution in line 2 correctly however failed to include y in line 3 as part of the interest for calculating interest in Bank. The student also found it difficult to relate what he found and the statement made in line 5 and 6 . He further, totally abandoned what he got in the subsequent workings. However, at the end of the workings the student was able to extract correct data from the question as can be seen.During a discussion, the student stated that he put the data in order to impress the examiner! When asked generally about question three, he responded 'somehow difficult'. $\mathrm{J}$ answered question 1 as follows:

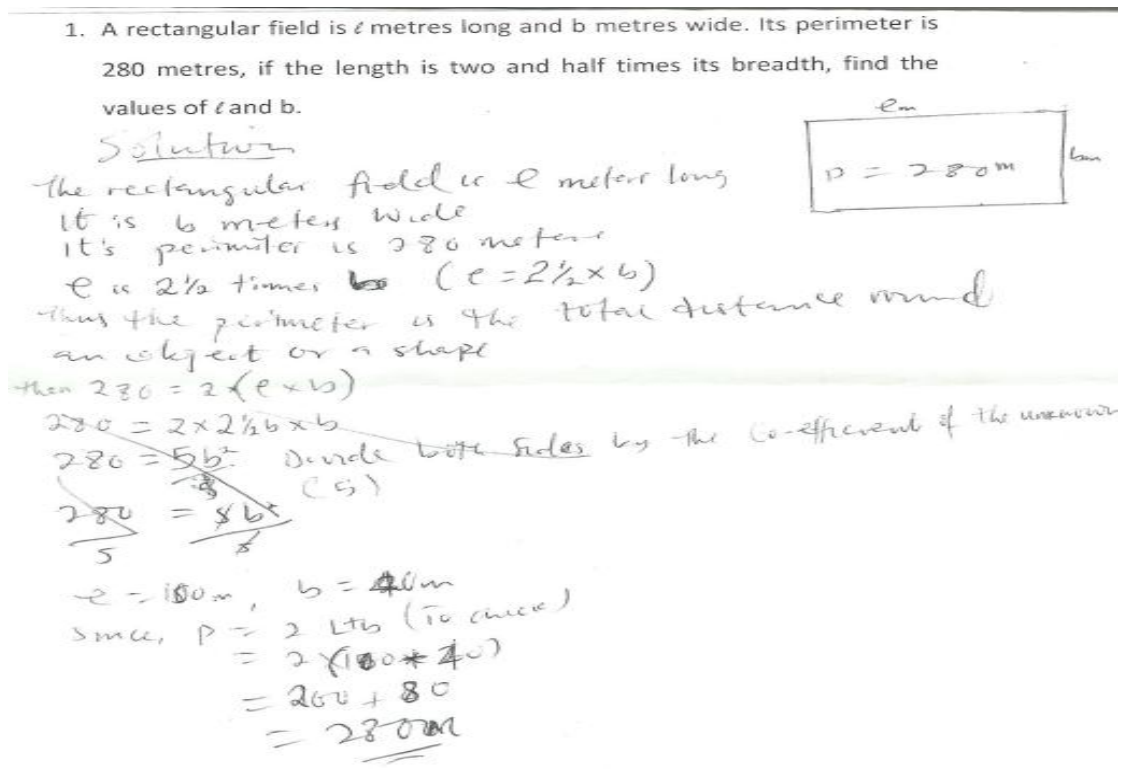


The student drew the diagram and labeled it correctly, also stated the definition of perimeter as "perimeter is the total distance round an object or shape". The student was also able to connect the relationship between the length and the breadth as given in the question, and was also able to write the formula and made substitution correctly. However, he found it difficult to relate the two simultaneous equations he obtained. But the student managed to guess the answers correctly without showing the procedures followed. During a discussion on question one, the student responded that the diagram 'makes it easy to solve the question as I can be referring to it'. The student responded that he came across this type of question long ago in JSS .The student also responded that he was taught word problems leading to simultaneous equations, however said that question one will not lead to simultaneous equations. He also responded that there is need to know the relationship between variables and also recalling formula is necessary. In question 2 the student was able to calculate percentages for the import duty correctly, but could not get the total cost correctly. It appears he did not understand the phrase forming part of the question; "total cost of goods including import duty". The student was also able to quote the relation for profit as "profit $=\mathbf{c p}-\mathbf{s p}$ " and was able to calculate the percentage but using a wrong data. During a discussion, the student stated that he came across this type of problem long ago in JSS.

Student K answered question 1 as follows:

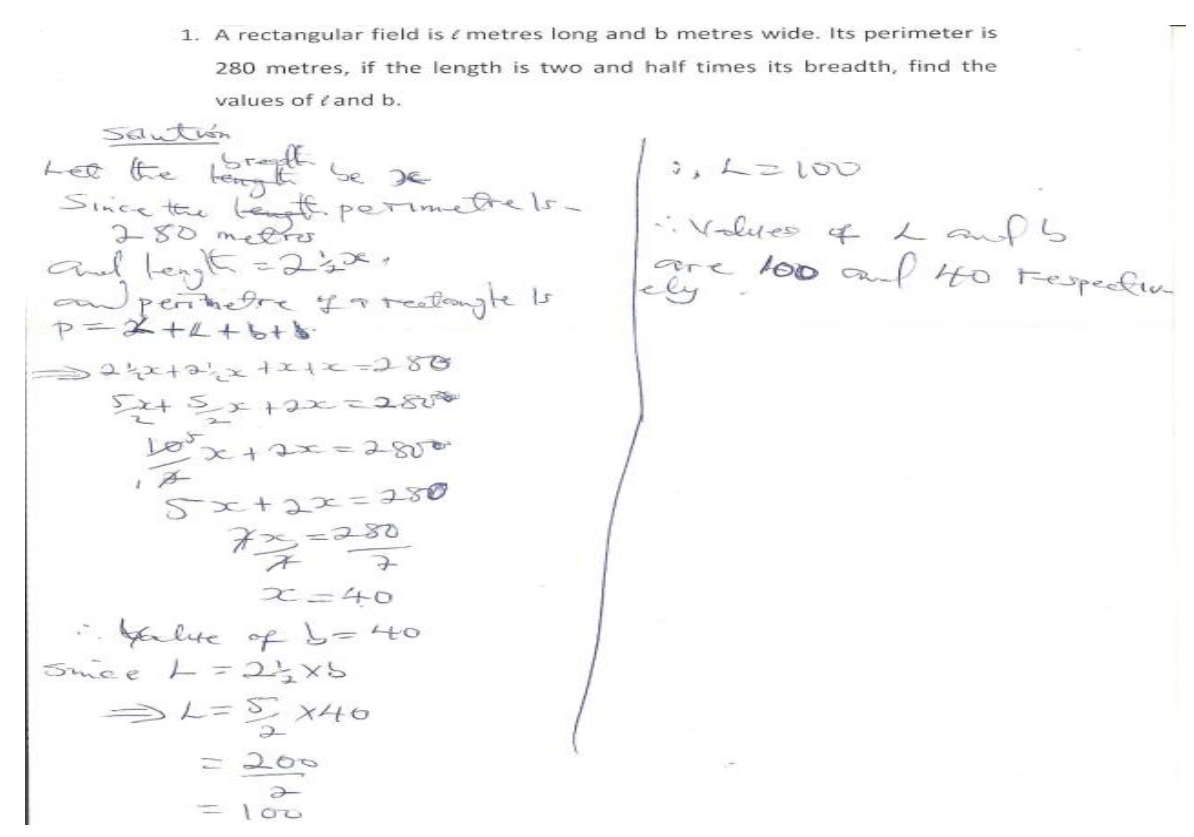

The student was able to use reasons in his workings, connect the relationship between the length and the breadth and obtained a correct answer. During a discussion, the student responded that diagrams are necessary in solving problems. But when asked why he did not draw one, he responded 'it will not affect my solution'. On whether he had ever come across a question like that, he responded 'yes in SS1'. On whether he was ever taught word problems leading to simultaneous equation, he responded 'yes in SS2'. When asked whether the question will lead to simultaneous equations he replied 'yes because it contains 1 and b', however, in his solution he did not show it as simultaneous equation. And when asked why he used $\mathrm{x}$ and $\mathrm{y}$ in his solution, he replied 'I am used to $\mathrm{x}$ and $\mathrm{y}$ '. On the issue of whether studying relationship is important, he replied 'yes, without forming relationship you cannot get the correct answer'. He also agreed that the use of formula is necessary in this question.

The students used various approaches to solve the given questions, but the calculations were not meaningful to lead them to correct answers. Almost all the students could not follow correct procedure in solving the questions. This could be due to their inability to extract meaning from the given situations. Despite some students attempted to the idea of "letting $x$ and $y$ to be the age of the woman and daughter respectively" in question 4 , and formed a correct equation from the first sentence, none of them however, was able to form the second equation which is an interpretation of a ratio.

\section{Concluding Remarks}

The research work was conducted in Demonstration Secondary School, Azare Bauchi State and has explored various approaches towards solving Mathematics words problems and may have relevance to schools with similar demographics. During the first contact students were very interested to participate in the research 
work. The interview held with the students revealed that they are aware of the nature of word problems. But when the questions were administered to the students, it was discovered that only $27 \%$ wrote something meaningful in few questions. It appearedstudents found the problems to be difficult;they were unable to solve them and could not give valid explanations for their workings. Furthermore, some students could not even attempt some questions out of the four questions given.

In general, the findings show that these students lack the necessary knowledge and skills to solve these types of problems. And it is important that learners are given the skills and knowledge to be able to solve questions on word problems. Therefore, teachers are required to give the students necessary and needed support to solve such problems.

\section{References}

[1]. Adams T. L. (2003): Reading Mathematics: More than words can say; An understanding of Mathematical literacy draws on many of the same skills as print literacy. The reading teacher, vol. 56(8)

[2]. Adler, J. (2004): Research Inside Teacher Education: The QUANTUM Project, its context, some results and its implications. A paper presented at the AERA conference in San Diego, April, 2004

[3]. James, W. W. (2002): introduction to Problem Solving. File//A:/info.httm.

[4]. Luneta, K. (2008): The professional development model, evaluating and enhancing international year book on teacher education. Wheeling instructional effectiveness through collaborative research. Paper presented at the international council on education for teaching (ICET) $53^{\text {rd }}$ World Assembly (July 14 - 17), Minho University, Broga, Portugal

[5]. Nancy, K. M. (1990): Learning Fractions with understanding; building on informal Knowledge. Journal for Research in Mathematics Education Vol. 21 No. $16-32$

[6]. Sello, M. (2011): Effective Instructional Approaches used by Teachers to teach Grade II Quadratic Equations in context of South African School in Lipopo.Proceedings of the $17^{\text {th }}$ National Congress of the Association for Mathematics Education of South Africa, Johannesburg Vol. I

[7]. Setati, M. (2005): Teaching Matematics in Primary Multilingual Classroom. Journal for Research in Mathematics Education, Vol. 36, No. 5, 447 - 466, South Africa University of Witwatersrand

[8]. Thompson, P. W. (1985): Experience, Problem Solving and Learning Mathematics: Considerations in Developing Mathematics Curricula. In E. A. Silver (Ed), Teaching and Learning Mathematical Problem Solving. Multiple Research Perspective, (pp 189 236) 